\title{
Exploring the possibilities for increasing the level of communi- cation between young entrepreneurs and business
}

\author{
Siyka Demirova ${ }^{1}$, Sibel Ahmedova ${ }^{1}$, Eredzep Musov ${ }^{1}$ and Soner Aziz ${ }^{1}$ \\ 1 - Technical University of Varna, Department of Industrial management, 9010, 1 Studentska Street, Varna, Bulgaria \\ Corresponding author contact: s demirova@tu-varna.bg
}

\begin{abstract}
With the development of technology, there is a growing need to improve communication between young entrepreneurs and businesses. The ability of these two groups to communicate effectively with each other would rebuild the poor communication between them and help establish a more efficient and sustainable relationship. The paper based on a research into the opportunities to increase the level of communication between young entrepreneurs and businesses, endeavors to propose a set of guidelines for their improved communication and cooperation.
\end{abstract}

Keywords: level of communication, young entrepreneurs, business, education

\section{Introduction:}

There are many aspects that determine the priority of the communication process in the business environment of the XXI century. The growing role of communication is of greatest importance for the provision of a favourable business environment that will enhance the sustainable development and corporate responsibility, while ensuring their business competitiveness. The ability to communicate effectively with employees and customers of a company, to stimulate trust and open dialogue in the management of an organization at the horizontal and vertical levels, is part of the winning formula of modern management (Cardon, 2016; Cardon, 2018).

Interaction is an integral part of modern business communications, one of the forms of human behavior, without which the exchange of information is not possible (Chaney, L. \& Martin, J., 2014). As a social phenomenon, the process of interaction means not only the spread but also the perception of this information at different levels. In structural terms, interaction is determined by the three interrelated aspects of communicative, interactive and proactive. It is the communicative component of interaction that is the basis of the successful modern communication. It is expressed in the constant exchange of information that feeds and maintains the network of interpersonal relationships and business contacts between internal audiences (Du-Babcock \& Tanaka, 2013).

In the age of new technologies, the two main forms of interaction that are extremely important for the effectiveness of the communication are: formal and informal (Guffey, M., 2007; Nickerson, C. ,2014). In the formal type of communication, the dynamics of interaction in internal company settings is maintained on the basis of pre-prepared and approved set of rules of conduct. In the informal form of communication, interaction between individuals is built on the basis of established professional and social roles individuals play within the respective social community (Markaki et al., 2013). This form is centred on emotional preferences and inner satisfaction with the selected framework of established contacts and relationships, where informal interpersonal communication is the basis of the existence of friendly societies, interest groups, intellectual circles, fan clubs and others. Unlike the informal, the formal type of interaction in the modern world presupposes acceptance and inclusion in the satisfaction of the social needs, adherence to the determined social tasks and compliance with the imposed professional rules and norms of behavior in the society (Keyton et al., 2013). From a purely psychological point of view, the process of interaction begins with a human need, when the communicator (sender) feels the need to convey information, share a desire, send a message and choose the ways and means to do so (Plumlee et al., 2016). On receiving the messages, the recipient converts them into thoughts or reactions and transmits them through feedback channels to confirm their proper understanding and determine their correct reading (Sims, 2015). Upon receiving the feedback, the communicator assesses whether the sent message has been received and correctly understood. This closes the whole process of communication. 
Communication is a dynamic process of information impact and interaction between people with different personality traits and individual characteristics in terms of their abilities, needs, expectations, perceptions, attitudes, values and more. Communication, further, is a process that takes place in specific economic, social, cultural, political, etc. conditions that also leave their mark on its course in form and content.

The main problems in communication between young people as potential entrepreneurs and businessmen are:

- the wrong way of perceiving the message

- dissemination of incorrect information through feedback channels

- lack of a suitable platform for direct communication between stakeholders

- lack of substantial professional rules and norms of behavior in the community

\section{Analysis of the opportunities to improve communication between young entrepreneurs and businesses}

The analysis of the opportunities for improved communication between young entrepreneurs and businesses presented in the paper is based on a survey conducted between students majoring in "Industrial Management" and "Technological Entrepreneurship and Innovation" studying at the Department of Industrial Management, TU -Varna.

For the purposes of the study, all the students in both majors are considered as potential young entrepreneurs owning different business ventures. This is supported by the fact that over $80 \%$ of the graduates have successfully undertaken new business ventures. The sample comprises 85 first- to fourth-year students including. Respondents indicated more than one answer to some of the questions.

A significant proportion (55\%) of the students indicate that they prefer to communicate by mobile phone, and $43 \%$ of them believe that face-to-face interaction provides better opportunities for communication. Only $2 \%$ of respondents say they prefer to communicate by email.

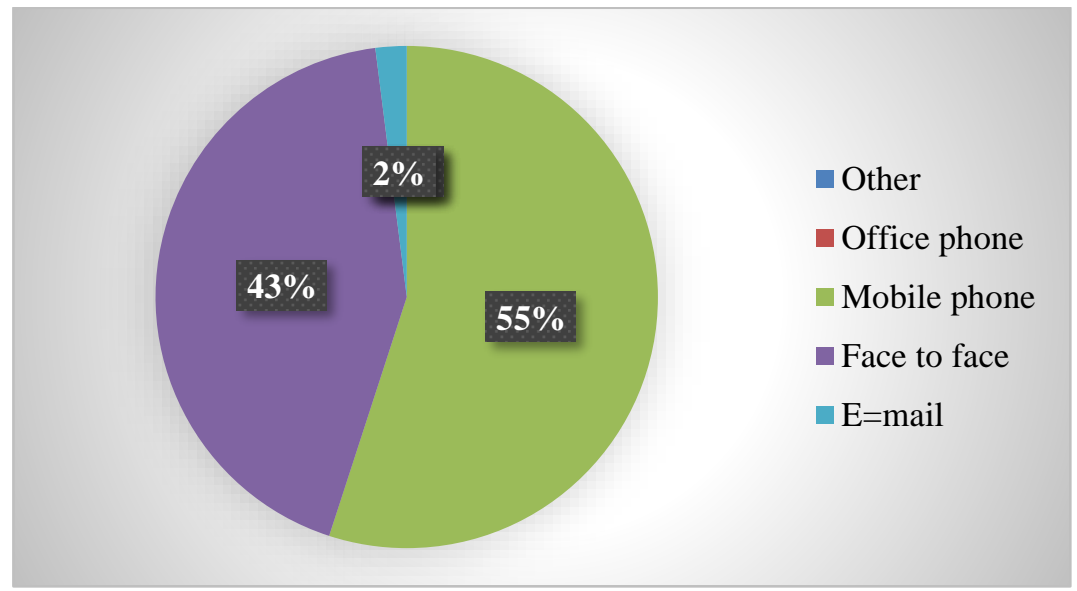

Fig. 1. What type of communication do you prefer?

The findings of the survey are probably attributable to the fact that in two-way communication a person experiences the need to feel the intonation of the other party and to place complete trust or take a negative attitude. It is much easier to form an opinion when a person is able to see the other party or parties in a "face to face" communication. As for e-mails, the formality does not inspire the feelings that people want to build for the other party (Fig. 1). 


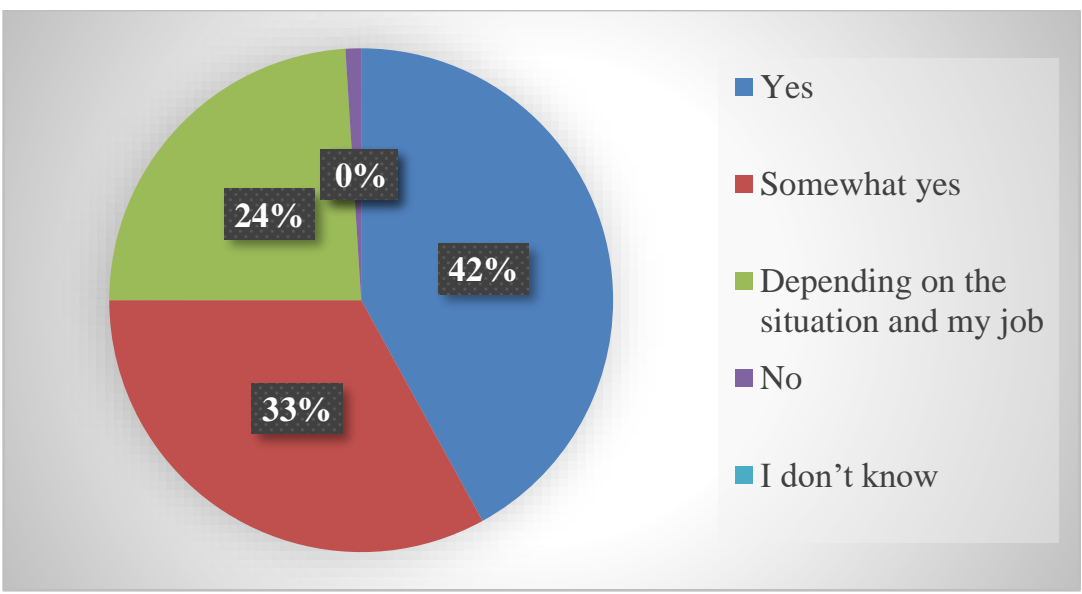

Fig. 2. - Do you think that student internships improve communication between young entrepreneurs and business representatives?

On the other hand, $42 \%$ of the students gave a positive answer that internships would strengthen the communication between young entrepreneurs and business representatives, which once again confirms that they prefer to communicate "face to face". 33\% of the surveyed students answered that student internships would to some extent improve their communication with business representatives. $24 \%$ of the respondents are of the opinion that the communication between young entrepreneurs and business representatives is largely dependent on the situation and the job position they hold (Fig. 2).

The survey into the opportunities for increasing the communication between young entrepreneurs and businesses shows that $24 \%$ of the students see great perspectives in the "Startup weekend" (Fig. 3 ). $23 \%$ of the respondents see real benefits in conducting an annual student competition in management with the participation of business representatives, and $22 \%$ believe that holding open meetings with businesses will create the conditions necessary for improving the communication between them. Students see fewer opportunities in conducting a "workshop" (16\%) and participating in internships programs $(15 \%)$.

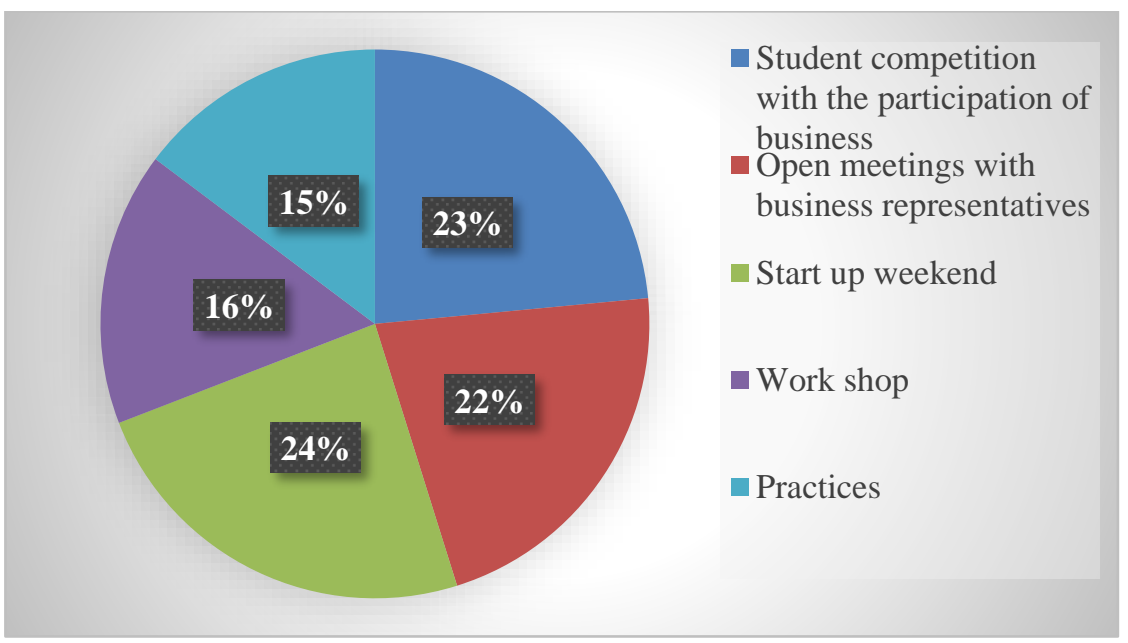

Fig. 3. - What are the opportunities to improve the communication between young entrepreneurs and businesses?

$85 \%$ of students indicate further that communication between young entrepreneurs and businesses would improve with the availability of an online platform, as this would allow for direct communication with them (Fig. 4). 13\% of the respondents say they cannot assess how much such an online platform would improve communication between them and businesses, and $2 \%$ say they do not need it. 


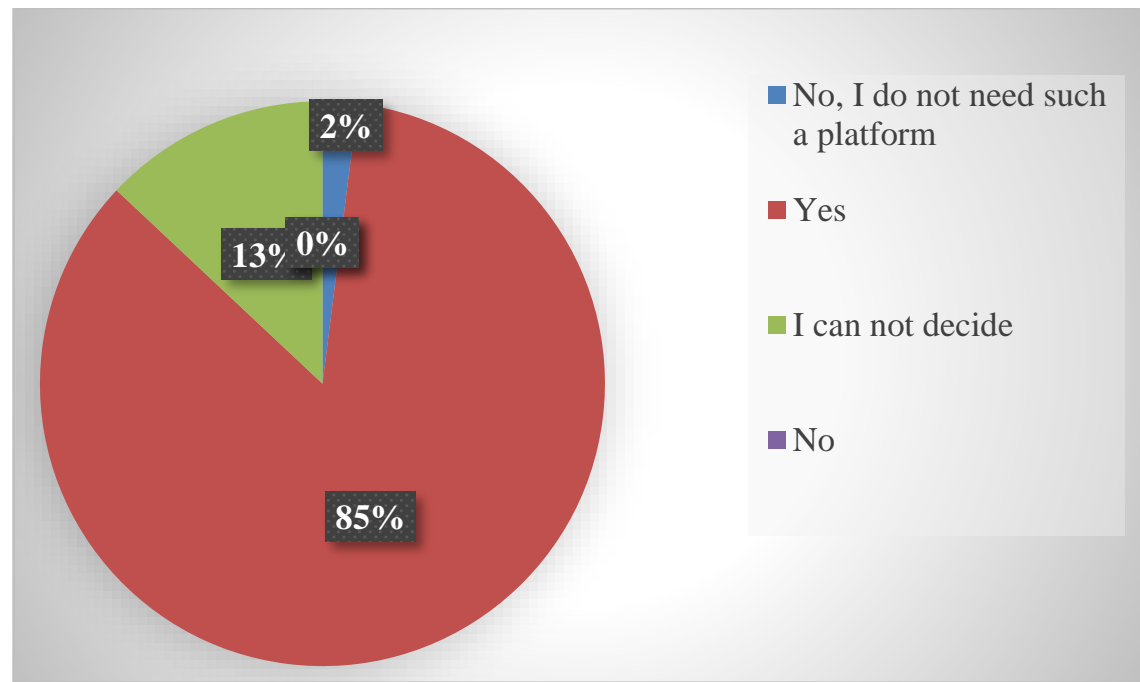

Fig. 4. - Would you like to have an online platform for direct communication with various companies and enterprises on the territory of the Republic of Bulgaria?

$78 \%$ of the students believe that there are cultural and social characteristics that affect the way young entrepreneurs and business representatives communicate. The main reasons given by the respondents are: the clash between the generations, the different socio-economic situation of the individuals that can trigger insurmountable problems in communication, regional (local) factors, educational factors (intellectual abilities of a person) and others. $22 \%$ of the surveyed students believe that cultural and social characteristics do not affect the communication between young entrepreneurs and business representatives (Fig. 5).

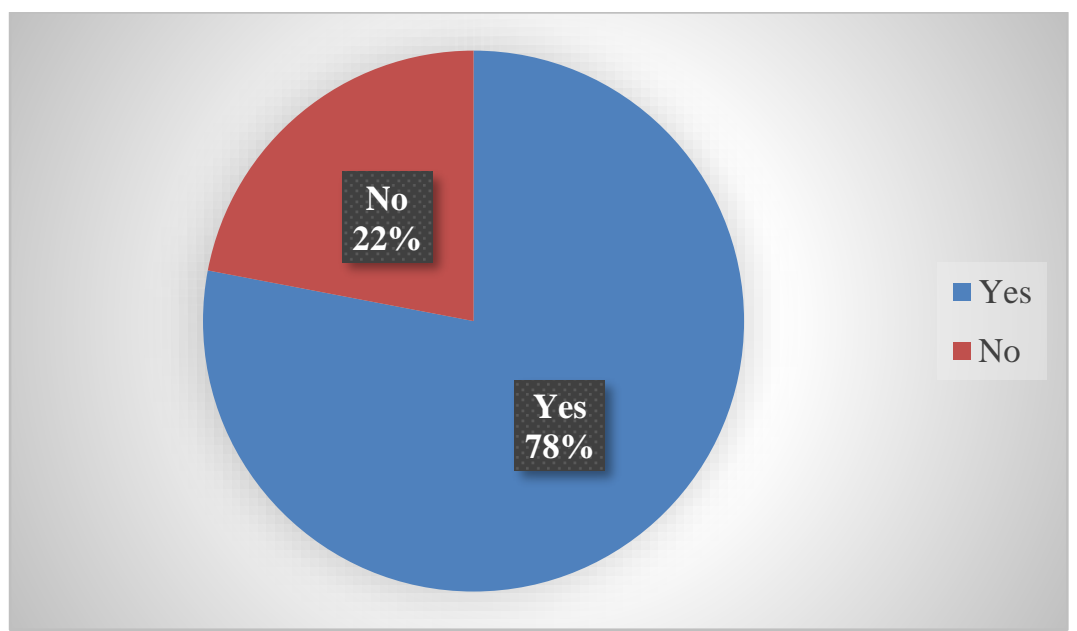

Fig. 5 - Are there any cultural and social characteristics that you think affectthe way the communication between young entrepreneurs and business representatives occur?

The various methods for improving the communication between businesses and young entrepreneurs are also essential. The survey shows that according to $30 \%$ of the students, it can be enhanced through informal interaction between universities and businesses. Moreover, 25\% of the students believe that the communication between businesses and young entrepreneurs would improve if business representatives take part in the learning process. The importance of the participation of company representatives in the examination commissions is reported by $10 \%$ of the respondents, and $17 \%$ of them believe that updating the higher education curricula with the participation of the business sector will lead to the training of such a staff that meets their labour demand requirements. 


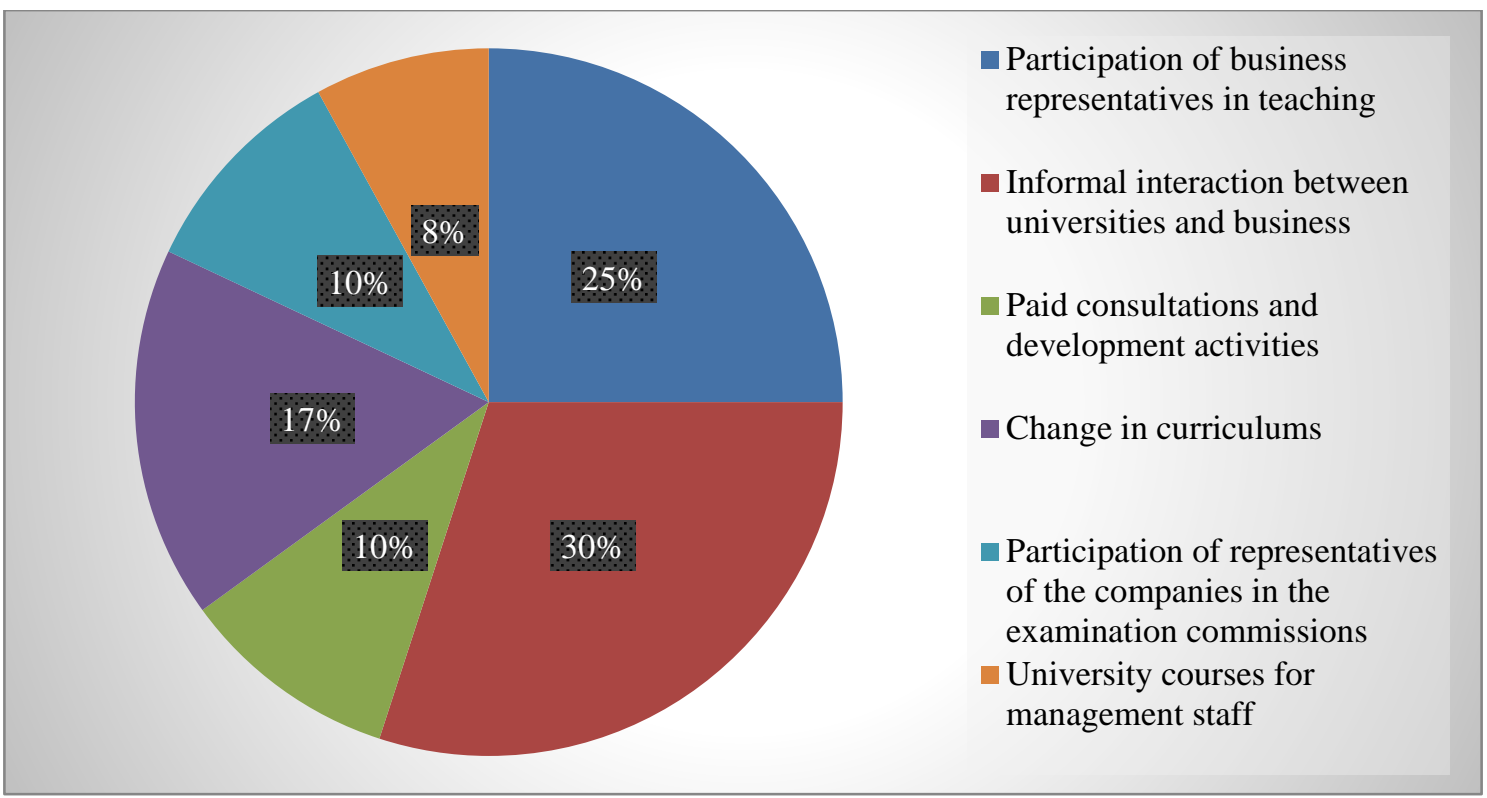

Fig. 6. Improving the relationship between businesses and young entrepreneurs

The surveyed students also point out the importance of the cooperation between the business sector and research institutes for advanced research and development and provision of training courses to upgrade workforce skills of employees in enterprises (Fig. 6).

\section{Results of exploring the possibilities for increasing the level of communication between young entrepreneurs and businesses}

- significant number of young people prefer to communicate via mobile phones, and less than a half think that "face to face" communication yields a better exchange of information

- a large percentage of students study believe that student internships would improve the level of communication between young people and business representatives

- surprising is the fact that only $2 \%$ of respondents prefer to communicate by email

- most of the respondents came up with excellent innovative ideas for opportunities to improve the level of communication between young entrepreneurs and businesses

- most of the respondents believe that the availability of an online platform will allow direct communication with businesses

\section{Guidelines for improving the communication between young entrepreneurs and business representatives}

Building a sustainable relationship between young entrepreneurs and businesses is the basis for developing a knowledge-based economy. The knowledge economy is a concept that encompasses advances in science and technology and the impact they have on economic and social life. Achieving smart growth and building a knowledge-based society will be accomplished by improving the quality of research and education. Attaining such a goal is linked to obtaining a number of results within five strategic priorities:

- the first is dedicated to research and technological development;

- the second is the business-education relationship; business and employment;

- the third priority is related to education as a factor for social inclusion;

- the fourth is associated with education and lifelong learning;

- the last refers to the improvement of the educational infrastructure; 
This can be achieved through:

- conducting events enabling direct communication between young entrepreneurs and business representatives;

- participation of business representatives in the development of university curriculum and course programs;

- joint contribution of students and businesses in national programs enabling special practices and internships;

- development of collaborative research projects between business representatives, researchers and young entrepreneurs and students.

\section{References}

Cardon (2016) Community, Culture, and Affordances in Social Collaboration and Communication, International Journal of Business Communication, 53(2), 141-147.

Cardon, P. (2018) Business Communication: Developing Leaders for a networked world. New York, NY: McGraw Hill 2018, p.100-129.

Chaney, L. \& Martin, J. (2014) Intercultural Business Communication, (6th ed). NY: Pearson Publishing.

Du-Babcock, B., \& Tanaka, H. (2013). A comparison of the communication behaviors of Hong Kong Chinese and Japanese business professionals in intracultural and intercultural decision-making meetings. Journal of Business and Technical Communication, 27(3), 263-287.

Guffey, M. (2007). Essentials of business communication (7th ed.). Mason, OH: Thomson/Wadsworth

Keyton, J., Caputo, J. M., Ford, E. A., Fu, R., Leibowitz, S. A., Liu, T., Polasik, S., Ghosh, P., Wu, C. (2013). Investigating verbal workplace communication behaviors. Journal of Business Communication, 50(2), 152-169. doi:10.1177/0021943612474990

Markaki, E. N., Sakas, D. P., \& Chadjipantelis, T. (2013). Communication management in business. The latent power for career development. Procedia-Social and Behavioral Sciences, 73, 319326

Nickerson, C. (2014). Business communication. In V. Bhatia., \& S. Bremner (Eds.), The Routledge handbook of professional communication (pp. 50-67). New York, NY: Routledge.

Plumlee, G. L., Wright, A., \& Wright, D. N. (2016). He wrote, she wrote: Gender similarities and differences in written business communication. The Journal of Business Diversity, 16(1), 78.

Sims, C. D. L. (2015). Competency and Connection: Undergraduate Students and Effective Email Messages. Communication Teacher, 29(3), 129-134.

Skinner, K. L., Hyde, S. J., \& McPherson, K. (2016). Improving Students' Interpersonal Skills through Experiential Small Group Learning. Journal of Learning Design, 9(1), 21-36. 